\title{
Dinâmica Populacional de Plantas Daninhas sob Diferentes Sistemas de Manejo nas Culturas de Milho e FeiJão ${ }^{1}$
}

\author{
Weed Population Dynamics Under Different Corn and Bean Production Systems
}

\author{
JAKELAITIS, A. ${ }^{2}$, FERREIRA, L.R. ${ }^{3}$, SILVA, A.A. ${ }^{3}$, AGNES, E.L. ${ }^{3}$, MIRANDA, G.V. ${ }^{3} \mathrm{e}$ \\ MACHADO, A.F.L. ${ }^{4}$
}

\begin{abstract}
RESUMO - Com o objetivo de avaliar a dinâmica populacional de plantas daninhas por meio de parâmetros fitossociológicos, realizou-se este trabalho com as culturas de milho e feijão em cultivos sucessivos, no período de novembro de 1998 a maio de 2001, em um Argissolo VermelhoAmarelo Câmbico, fase terraço, em Viçosa-MG. A comunidade de plantas daninhas era composta por Amaranthus deflexus, Brachiaria plantaginea, Cyperus rotundus, Galinsoga parviflora, Mucuna aterrima e Oxalis latifolia. Os tratamentos foram constituídos de dois sistemas de manejo do solo (plantios convencional e direto) e duas finalidades de uso da cultura do milho (grão e silagem), em blocos com quatro repetições. No plantio convencional, antes da semeadura das culturas, o solo foi arado e gradeado, e, no plantio direto, foi realizada a dessecação das plantas daninhas com herbicidas sistêmicos. As avaliações de plantas daninhas na cultura do milho foram realizadas antes e após a aplicação dos herbicidas nicosulfuron e atrazine em pós-emergência (aos 20 e 55 DAE, respectivamente) no ano agrícola 1999/00, e após a aplicação de atrazine e metolachlor em pré-emergência (aos 20 DAE) em 2000/01. Em se tratando do feijoeiro, as avaliações também foram feitas antes e após a aplicação dos herbicidas fluazifopp-butil e fomesafen, em pós-emergência aos 20 e 40 DAE, respectivamente. A dinâmica populacional foi avaliada por meio do uso de parâmetros fitossociológicos baseados na densidade, freqüência e biomassa das espécies amostradas. Verificou-se aos 20 DAE, antes da aplicação dos herbicidas em ambas as culturas (milho e feijão), maior densidade e importância relativa das espécies dicotiledôneas no plantio direto. No plantio convencional constatou-se maior densidade, dominância e importância relativa de Cyperus rotundus. Após aplicação dos herbicidas seletivos, Cyperus rotundus foi a espécie de maior importância relativa em todos os sistemas estudados. Em ambas as finalidades de uso do milho, Cyperus rotundus teve sua população reduzida no plantio direto, quando comparado com o convencional.
\end{abstract}

Palavras-chave: fitossociologia, herbicidas, plantios direto e convencional, Cyperus rotundus.

ABSTRACT - The objective of this study was to evaluate weed dynamics based on phytosociological parameters. The experiment was conducted with corn and bean crops cultivated in succession from November, 1998 to May, 2001 in a Cambic Yellow Red Argisol soil, terrace phase, in Viçosa, MG. The weed community consisted of Amaranthus deflexus, Brachiaria plantaginea, Cyperus rotundus, Galinsoga parviflora, Mucuna aterrima and Oxalis latifolia. The treatments consisted of two soil management systems (conventional and no-tillage) and corn use purposes (grain and silage) in blocks with four replicates. Under conventional tillage, the soil was moldboard plowed before sowing, and under no-tillage, weed desiccation was carried out with glyphosate and 2,4-D. Weed evaluations occurred at 20 and 55 days after emergence in 1999/00 and at 20 days after emergence in 2000/01. In both years, evaluations were accomplished immediately before or after application of selective herbicides. For the bean crop, evaluations were also carried out before and after fluazifop-p-butyl and fomesafen application in post emergence, at 20 and 40 days after emergence, respectively. Weed population dynamics was evaluated through phytosociological parameters based on density, biomass and frequency of the sampled species. The results showed that at 20 days after emergence before

Recebido para publicação em 13.9.2002 e na forma revisada em 2.4.2003.

2 Pós-graduando, D.S., Dep. de Fitotecnia da Universidade Federal de Viçosa - UFV, 36571-000 Viçosa-MG. ${ }^{3}$ Prof. do Dep. de Fitotecnia da UFV; ${ }^{4}$ Estudante de Agronomia da UFV. 
herbicide application, greater density and relative importance for dicot weeds were observed under no-tillage for both corn and bean crops. Under conventional tillage, there was greater density, dominance and relative importance of Cyperus rotundus. After herbicide application, Cyperus rotundus had the greatest relative importance in both systems evaluated. For both corn use purposes, Cyperus rotundus had its population reduced under no-tillage, compared to conventional tillage.

Key words: phytosocioloy, herbicides, no-tillage and conventional tillage, Cyperus rotundus.

\section{INTRODUÇÃO}

Dinâmica populacional de plantas daninhas refere-se a mudanças na composição da comunidade infestante no tempo, considerando o número e a dominância relativa de cada espécie no agroecossistema (Zelaya et al., 1997). A heterogeneidade da comunidade de plantas daninhas é definida pela variabilidade relativa das espécies no agroecossistema, a qual é alta nas comunidades onde o número de espécies é elevado e ocorre distribuição equivalente dessas espécies na área (Krebs, 1985).

A composição das populações de plantas daninhas em um agroecossistema é reflexo de suas características edáficas e climáticas e das práticas agronômicas adotadas, como manejo do solo e aplicação de herbicidas (Godoy et al., 1995). Assim, o plantio direto pode alterar a população de plantas daninhas, a dinâmica do banco de sementes do solo e a eficiência de herbicidas aplicados em pré-emergência, devido à cobertura do solo com resíduos vegetais (Crutchfield et al., 1986; Johnson et al., 1989; Bulher et al., 1995). A presença de palhada na superfície do solo antes do plantio também pode modificar as condições para a germinação de sementes e emergência das plântulas, em razão do efeito físico de cobertura e da liberação de substâncias alelopáticas.

Diferentes sistemas de manejo do solo condicionam as sementes a microambientes do solo, devido a alterações em suas propriedades físico-químicas e nas condições da superfície do solo (Mulugueta \& Stoltenberg, 1997). Essas mudanças podem influenciar a germinação e o estabelecimento de plantas daninhas, por causa da criação de condições variáveis de umidade e aeração. Também a distribuição das sementes no perfil do solo pode ser alterada, causando modificações na dinâmica populacional das plantas daninhas. O preparo convencional do solo incorpora as sementes de modo mais uniforme no perfil trabalhado, proporcionando a distribuição horizontal e vertical de sementes das plantas daninhas. Essa distribuição das sementes no perfil do solo é influenciada pela freqüência de preparo, dando origem a persistentes bancos de sementes no solo (Lindquist \& Maxwell, 1991; Guersa \& Martinéz-Guersa, 2000). Segundo Oryokot et al. (1997), em diferentes sistemas de manejo, por causa das variações temporais e espaciais dependentes da estrutura genética da população e dos fatores ambientais ligados a esses sistemas, torna-se difícil predizer a emergência de plantas daninhas no agroecossistema.

Pitelli (2000a, b) afirma que os índices fitossociológicos são importantes para analisar o impacto que os sistemas de manejo e as práticas agrícolas exercem sobre a dinâmica de crescimento e ocupação de comunidades infestantes em agroecossistemas. Esses índices, de acordo com o autor, são descritos principalmente pela densidade relativa, freqüência relativa, dominância relativa e importância relativa das espécies. Assim, a densidade relativa reflete a participação numérica de indivíduos de uma determinada espécie na comunidade; a freqüência relativa refere-se à porcentagem que representa a freqüência de uma população em relação à soma das freqüências das espécies que constituem a comunidade; a dominância relativa representa o ganho de biomassa de uma determinada espécie na comunidade; e a importância relativa é uma avaliação ponderada desses índices.

O objetivo deste trabalho foi avaliar, por meio da fitossociologia, os efeitos de sistemas de manejo do solo (plantios direto e convencional) e das finalidades de uso da cultura do 
milho (grão e silagem) sobre a dinâmica populacional de plantas daninhas.

\section{MATERIAL E MÉTODOS}

O experimento, que envolveu a cultura do milho e do feijão em cultivos sucessivos, foi conduzido durante três anos agrícolas (1998/ 99, 1999/00 e 2000/01), em área experimental da Universidade Federal de Viçosa. O solo onde foi conduzido o experimento é classificado como Argissolo Vermelho-Amarelo Câmbico, fase terraço, textura argilosa, com $146 \mathrm{mg} \mathrm{dm}^{-3} \mathrm{de}$ $\mathrm{P}, 141 \mathrm{mg} \mathrm{dm}^{3}$ de $\mathrm{K}, 3,4 \mathrm{cmol}_{\mathrm{c}} \mathrm{dm}^{-3}$ de Ca e 5,1 dag $\mathrm{kg}^{1}$ de matéria orgânica. Os tratamentos foram constituídos de dois sistemas de manejo do solo (plantios convencional e direto) e duas finalidades de uso da cultura do milho (grão e silagem), em blocos com quatro repetições. A área total de cada parcela foi de $90 \mathrm{~m}^{2}$ $(9 \times 10 \mathrm{~m})$, separadas entre si por bordadura de $1 \mathrm{~m}$.

A comunidade de plantas daninhas que antecedeu a instalação do experimento era composta por tiririca (Cyperus rotundus), botão-de-ouro (Galinsoga parviflora), caruru (Amaranthus deflexus), capim-marmelada (Brachiaria plantaginea), mucuna (Mucuna aterrima) e trevo (Oxalis latifolia). Durante o período de condução do experimento (1998 a 2001), embora tenham sido cultivadas três safras de milho e duas de feijão, foram apresentados e discutidos apenas os resultados a partir do segundo ano de condução do experimento.

A semeadura do milho para grão e silagem foi feita em novembro/dezembro de cada ano, sete dias após a dessecação das plantas daninhas com glyphosate + 2,4-D $(1,44+$ $0,335 \mathrm{~kg} \mathrm{had),} \mathrm{nas} \mathrm{parcelas} \mathrm{onde} \mathrm{se} \mathrm{realizou} \mathrm{o}$ plantio direto. No plantio convencional não foi realizada a dessecação, sendo o preparo do solo feito com uma aração e duas gradagens, para uniformização do terreno. Nos dois sistemas de condução da cultura do milho, a adubação de plantio foi de $32 \mathrm{~kg} \mathrm{ha}^{-1}$ de $\mathrm{N}, 112 \mathrm{~kg} \mathrm{ha}^{-1}$ de $\mathrm{P}_{2} \mathrm{O}_{5}$ e $64 \mathrm{~kg} \mathrm{ha}^{-1}$ de $\mathrm{K}_{2} \mathrm{O}$. Foram utilizados os híbridos AG-1051, BRS 3060 e AG-122, nos anos agrícolas 1998/99, 1999/00 e 2000/01, respectivamente, cultivados no espaçamento de $90 \mathrm{~cm}$ entre as fileiras, obtendo aproximadamente 67.000 plantas ha ${ }^{-1}$. A adubação nitrogenada de cobertura foi realizada quatro semanas após a emergência das plântulas, na dose de $50 \mathrm{~kg} \mathrm{ha}^{-1}$ de $\mathrm{N}$.

A aplicação dos herbicidas seletivos à cultura do milho foi realizada em pós-emergência nos anos agrícolas 1998/99 e 1999/00, aos 20 dias após a emergência (DAE), sendo aplicada a mistura em tanque de atrazine e nicosulfuron ( 1,50 e $\left.0,028 \mathrm{~kg} \mathrm{ha}^{-1}\right)$. No ano agrícola 2000/01, procedeu-se à aplicação da mistura formulada de atrazine e metolachlor $(1,4+$ $2,1 \mathrm{~kg} \mathrm{ha}^{1}$ ) em pré-emergência.

O milho para silagem quando atingiu o estádio farináceo-duro foi colhido mecanicamente e retirado da área, ao passo que os restos culturais do milho para grão foram espalhados na superfície do solo no plantio direto durante a colheita; no plantio convencional, esse material foi incorporado ao solo, para o plantio posterior do feijão. Antes da semeadura do feijão, no plantio direto foi realizada a dessecação da vegetação remanescente com glyphosate $\left(1,44 \mathrm{~kg} \mathrm{ha}^{-1}\right)$; no plantio convencional foi realizado o mesmo procedimento descrito para a cultura do milho.

A cultura do feijão cultivar Sangue de Boi foi implantada em abril/maio de cada ano, utilizando-se população de 230.000 plantas ha $^{-1}$ em espaçamento entre linhas de $50 \mathrm{~cm}$. A adubação de semeadura foi feita com $16 \mathrm{~kg} \mathrm{ha}^{1}$ de N, $56 \mathrm{~kg} \mathrm{ha}^{-1}$ de $\mathrm{P}_{2} \mathrm{O}_{5}$ e $32 \mathrm{~kg} \mathrm{ha}^{-1}$ de $\mathrm{K}_{2} \mathrm{O}$. O controle de plantas daninhas foi realizado com os herbicidas fomesafen e fluazifop-p-butil $\left(0,175\right.$ e $\left.0,14 \mathrm{~kg} \mathrm{ha}^{-1}\right)$, aplicados aos 20 DAE.

Na cultura do milho, as avaliações de plantas daninhas foram realizadas antes e após aplicação dos herbicidas seletivos, no ano agrícola 1999/00 (20 e 55 DAE, respectivamente), e, em 2000/01, apenas aos 20 DAE. No caso da cultura do feijão, as avaliações foram feitas aos 20 e $40 \mathrm{DAE}$, antes e após a aplicação dos herbicidas fomesafen e fluazifopp-butil. A coleta das plantas daninhas foi realizada utilizando um quadrado de $0,5 \mathrm{~m}$ de lado, em quatro amostragens ao acaso na parcela. As plantas daninhas coletadas foram levadas ao laboratório, onde foram separadas por espécie e contadas. Em seguida, foram secadas à estufa de ventilação forçada, por 72 horas a $70{ }^{\circ} \mathrm{C}$, para determinação da biomassa seca. Uma vez obtidas a densidade de indivíduos e a biomassa seca, foi realizada

Planta Daninha, Viçosa-MG, v.21, n.1, p.71-79, 2003 
análise descritiva, através de parâmetros fitossociológicos representados pela densidade relativa, pelas freqüências absoluta e relativa, pela dominância relativa, pelo índice do valor de importância e pela importância relativa das espécies componentes da comunidade infestante de cada tratamento, conforme Pitelli (2000a, b).

Os dados climatológicos referentes a temperatura média $\left({ }^{\circ} \mathrm{C}\right)$, umidade relativa $(\%)$ e ocorrência e intensidade de chuva $(\mathrm{mm})$ durante a condução do experimento são apresentados na Figura 1.

\section{RESULTADOS E DISCUSSÃO}

A composição da comunidade infestante durante a condução do experimento foi de 25 espécies, distribuídas em 25 gêneros e 12 famílias, observando-se maior diversidade de espécies no plantio direto, com predominância de dicotiledôneas, ciperáceas e gramíneas.
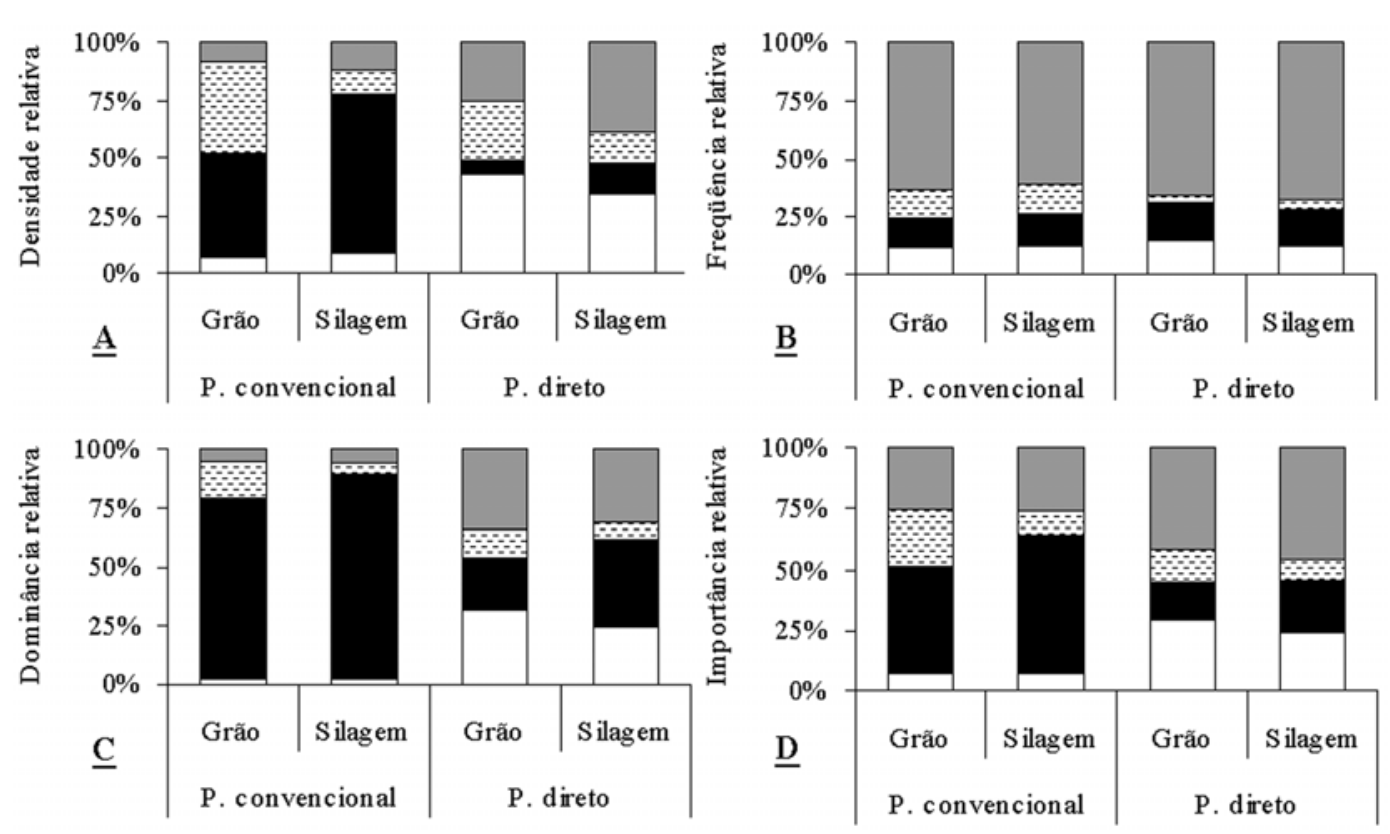

Amaranthus deflexus

Cyperus rotundus
Os resultados dos índices fitossociológicos representados pela densidade, freqüência, dominância e importância relativa das principais populações de plantas daninhas presentes na comunidade infestante da cultura do milho (anos agrícolas 1999/00 e 2000/01) e do feijão (1999/00) estão apresentados nas Figuras 2 a 6.

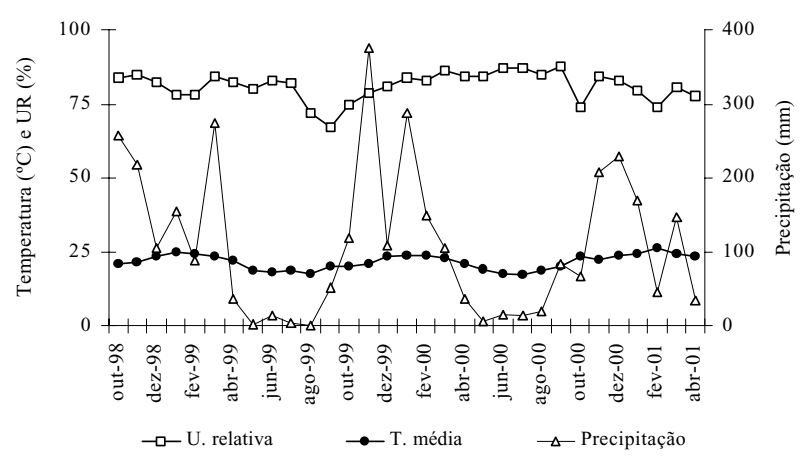

Figura 1 - Dados climatológicos coletados durante o período de condução do experimento. Viçosa-MG, 2001. 
No plantio convencional da cultura do milho, Cyperus rotundus apresentou maior densidade relativa, ou seja, foi a espécie mais numerosa da comunidade infestante, seguida por Galinsoga parviflora, Amaranthus deflexus (Figura 2A) e Oxalis latifolia (Figura 6A). A participação de Cyperus rotundus no sistema convencional em ambos os anos agrícolas representou entre 78 e $87 \%$ dos indivíduos da comunidade infestante de milho para grão e silagem, respectivamente. De acordo com Godoy et al. (1995) e Ferreira et al. (2000), o uso do preparo convencional favorece a propagação e o estabelecimento desta espécie, devido à quebra de dormência ocasionada pela divisão da seqüência de tubérculos e pela eliminação da dominância apical exercida pelo tubérculo distal. Em decorrência disso, para as demais espécies, as baixas densidades populacionais encontradas podem ser atribuídas à competição interespecífica exercida por Cyperus rotundus.

No plantio direto aos 20 DAE, verificou-se predominância de Amaranthus deflexus para
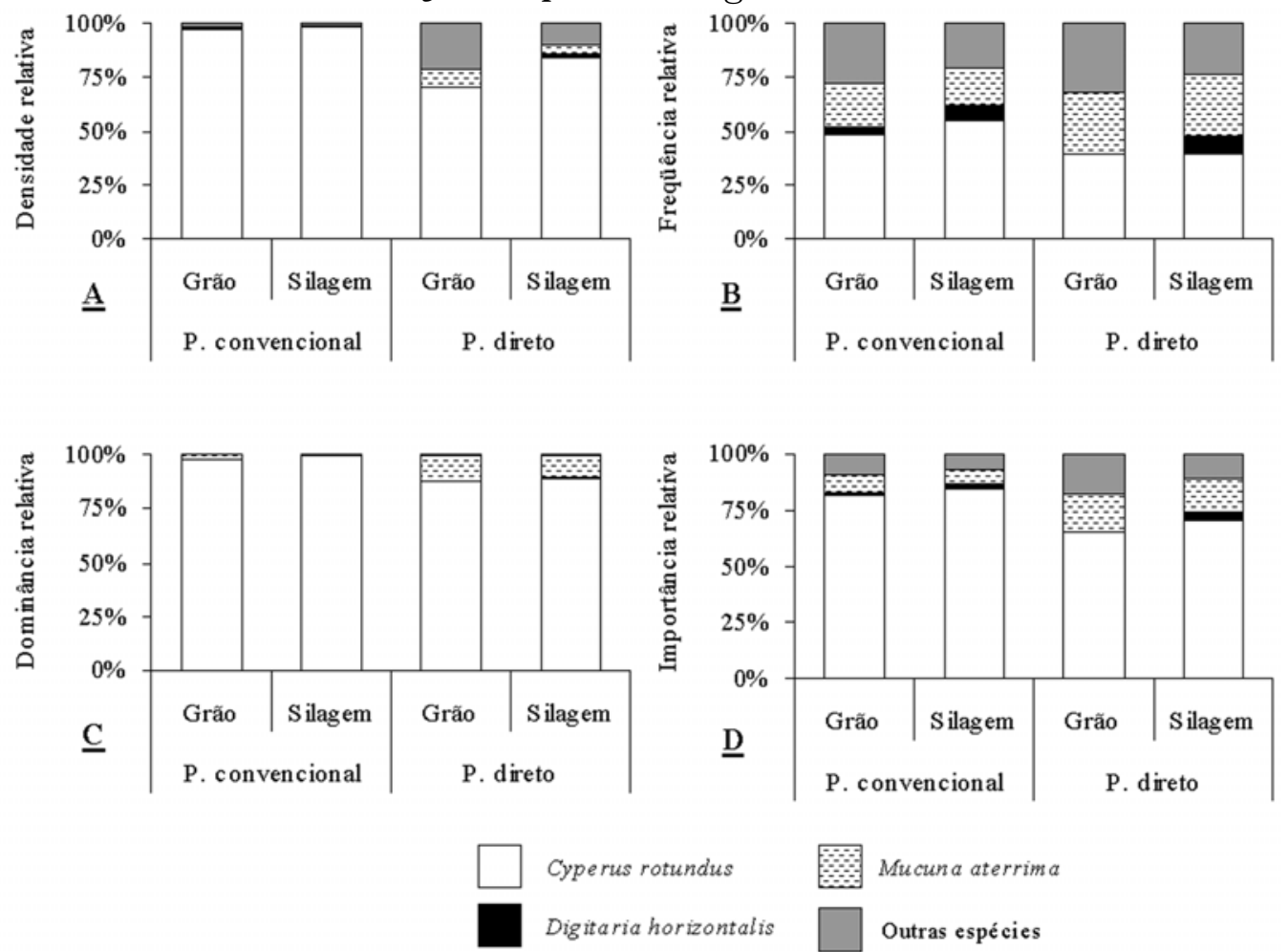

Mucuna aterrima

Outras espé cies

Figura 3 - Efeitos dos sistemas de manejo do solo (plantios convencional e direto) e das finalidades de uso do milho (grão e silagem) no segundo ano de condução sobre a densidade (A), freqüência (B), dominância (C) e importância relativa (D) das espécies daninhas na cultura do milho, avaliadas aos 55 DAE após a aplicação dos herbicidas nicosulfuron e atrazine em pósemergência. Viçosa-MG, 2001. (Outras espécies corresponde a Brachiaria plantaginea, Eleusine indica e Oxalis latifolia). 
Em se tratando do feijoeiro, a densidade relativa de Cyperus rotundus também permaneceu superior no plantio convencional, quando comparado com o direto, porém ela foi suplantada por Coronopus didymus, avaliada aos 20 DAE (Figura 4A). Essa redução na densidade pode ser atribuída às condições climáticas nesse período (Figura 1), e Cyperus rotundus, por ser uma espécie $\mathrm{C}_{4}$, requer ótimas condições de umidade e temperatura para seu desenvolvimento (Meirong, 1993). Da mesma forma, após aplicação dos herbicidas seletivos ao feijoeiro, a densidade das espécies de propagação vegetativa (Cyperus rotundus e Oxalis latifolia) aumentou, em detrimento daquelas de propagação seminífera (Figura 5A).

Verificou-se equivalência nos valores das freqüências relativas das espécies encontradas quando as avaliações precederam a aplicação dos herbicidas seletivos às culturas de milho (Figura 2B) e feijão (Figura 4B), cujos valores das demais espécies ultrapassaram 50\% da freqüência relativa da comunidade de cada tratamento. Nesse caso, houve apenas pequeno padrão de variação para Galinsoga parviflora no plantio direto, que apresentou menor freqüência nas amostragens efetuadas e maior tendência de agregação na população (Figura 2B).

Nas avaliações realizadas após a aplicação dos herbicidas seletivos de ambas as culturas (Figuras 3B, 5B e 6B), observaram-se reduções significativas da freqüência relativa de outras espécies nos tratamentos estudados. Entretanto, menor redução da freqüência das demais espécies foi observada no plantio direto, avaliado após aplicação em pré-emergência dos herbicidas (atrazine + metolachlor) no milho (Figura 6B). Esse comportamento é explicado pela interceptação desses herbicidas pelos resíduos vegetais, oriundos da dessecação de plantas daninhas em pré-plantio. A presença desses resíduos na superfície do solo pode diminuir a eficiência dos herbicidas aplicados
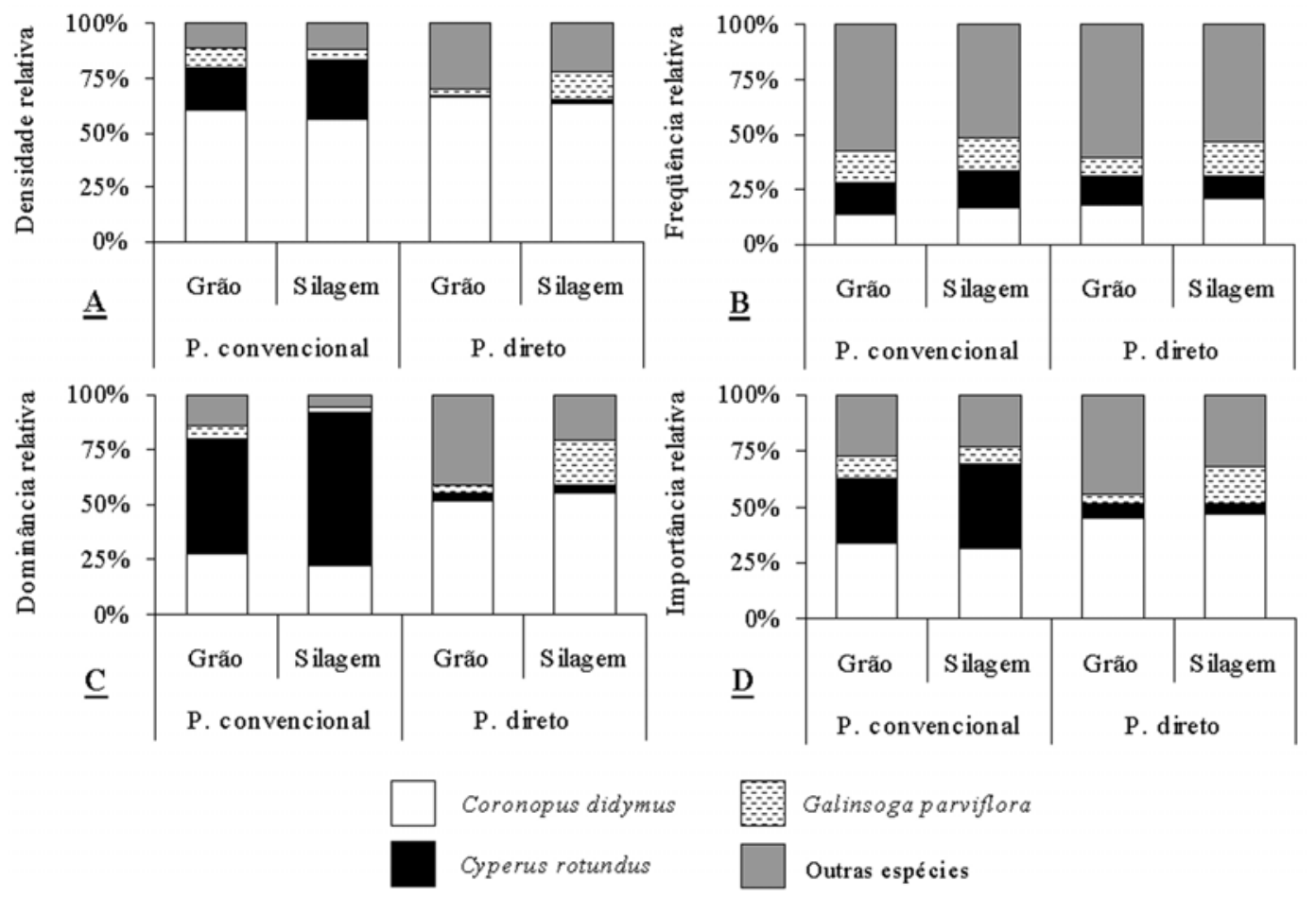

Figura 4 - Efeitos dos sistemas de manejo do solo (plantios convencional e direto) e das finalidades de uso do milho (grão e silagem) no segundo ano de condução sobre a densidade (A), freqüência (B), dominância (C) e importância relativa (D) das espécies daninhas na cultura do feijão, avaliadas aos 20 DAE antes da aplicação dos herbicidas fluazifop-p-butil e fomesafen em pós-emergência. Viçosa-MG, 2001. (Outras espécies corresponde a Amaranthus deflexus, Bidens pilosa, Brachiaria plantaginea, Digitaria horizontalis, Emilia sonchifolia, Euphorbia heterophylla, Mucuna aterrima, Oxalis latifolia, Raphanus raphanistrum, Sinapsis arvensis, Solanum americanum, Sonchus oleraceus e Stachys arvensis). 

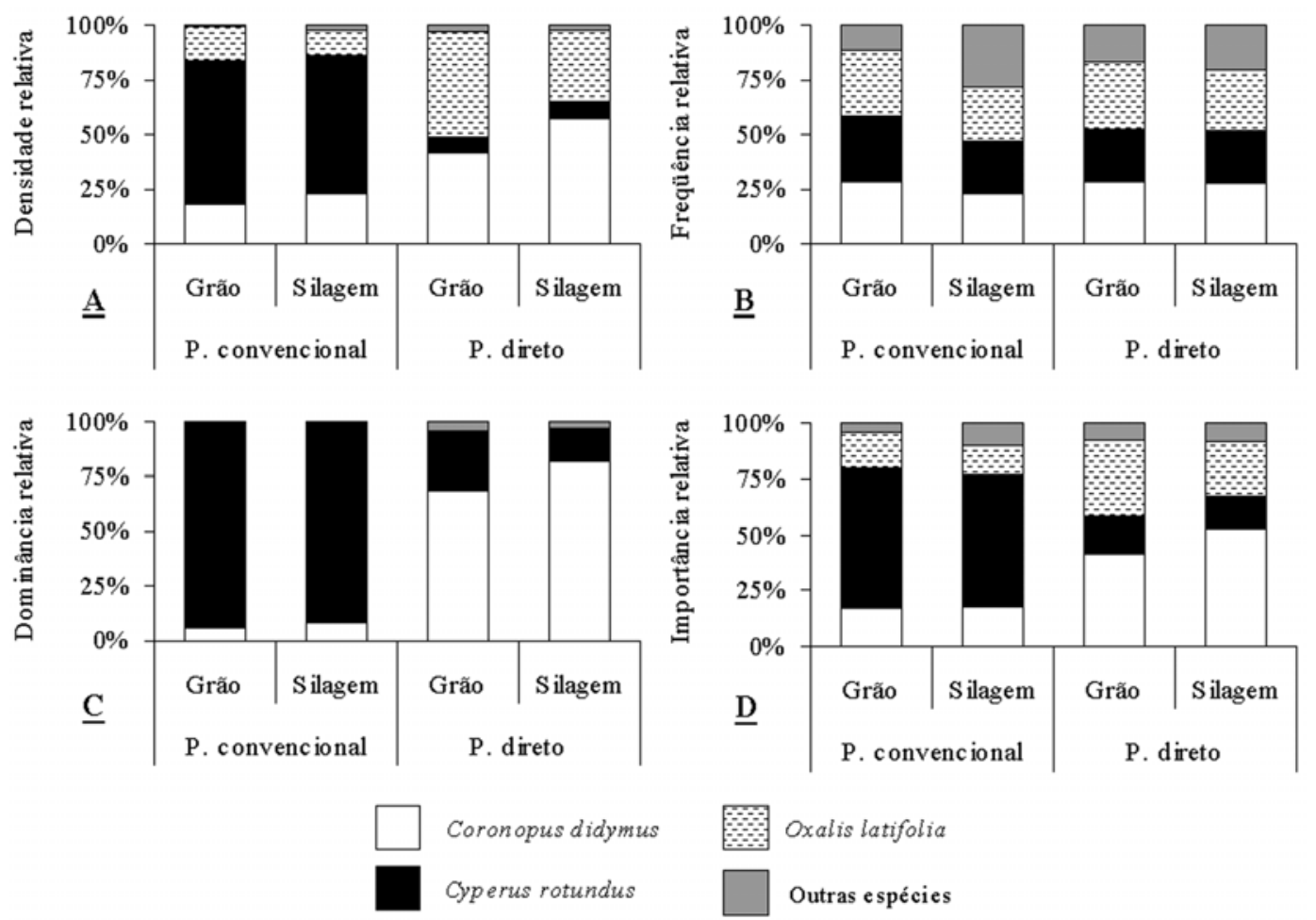

Figura 5 - Efeitos dos sistemas de manejo do solo (plantios convencional e direto) e das finalidades de uso do milho (grão e silagem) no segundo ano de condução sobre a densidade (A), freqüência (B), dominância (C) e importância relativa (D) das espécies daninhas na cultura do feijão, avaliadas aos 40 DAE após a aplicação dos herbicidas fluazifop-p-butil e fomesafen em pós-emergência. Viçosa-MG, 2001. (Outras espécies corresponde a Amaranthus deflexus, Bidens pilosa, Digitaria horizontalis, Euphorbia heterophylla, Galinsoga parviflora, Gnaphalium spicatum, Mucuna aterrima e Solanum americanum).

em pré-emergência, devido à interrupção do movimento destes até o solo, atribuída principalmente à retenção e/ou possibilidade de degradação e volatilização do herbicida interceptado (Ghadiri et al., 1984; Johnson et al., 1989).

Observando a dominância relativa das espécies no plantio convencional, nota-se que ocorreram maiores valores para Cyperus rotundus, que atingiu 84 e $88 \%$ da dominância da comunidade para as finalidades de uso do milho para grão e silagem, respectivamente (Figuras 2C a 6C). De acordo com Miles et al. (1996), esse comportamento é reflexo da alta taxa de crescimento inicial desta espécie, proveniente da elevada acumulação de biomassa pelas manifestações epígeas iniciais. Isso é observado, também, no plantio direto para ambas as finalidades de uso da cultura do milho, onde, apesar de ocorrerem menores valores de densidade relativa para Cyperus rotundus, em relação às demais espécies, seus valores de dominância relativa foram elevados.
Entre as dicotiledôneas, constatou-se relação direta entre os índices de densidade e dominância relativa. Desse modo, as maiores populações acumularam mais biomassa, prevalecendo os maiores valores para Amaranthus deflexus no plantio direto e Galinsoga parviflora no convencional (Figura 2C); Mucuna aterrima (Figuras 3C e 6C) e Oxalis latifolia (Figura 6C), no plantio direto da cultura do milho; e Coronopus didymus, em ambos os sistemas de manejo na cultura do feijão (Figuras 4C e 5C).

No plantio convencional observou-se maior importância relativa para Cyperus rotundus, em razão especialmente dos maiores valores de densidade e dominância dos indivíduos, além da elevada freqüência da espécie em todas as amostragens efetuadas. Esse fato contribuiu para redução da importância das demais espécies, entre estas, principalmente, Galinsoga parviflora (Figura 2D) e Oxalis latifolia (Figura 3D), na cultura do milho, e Coronopus didymus (Figuras 4D e 5D), na do feijoeiro. 

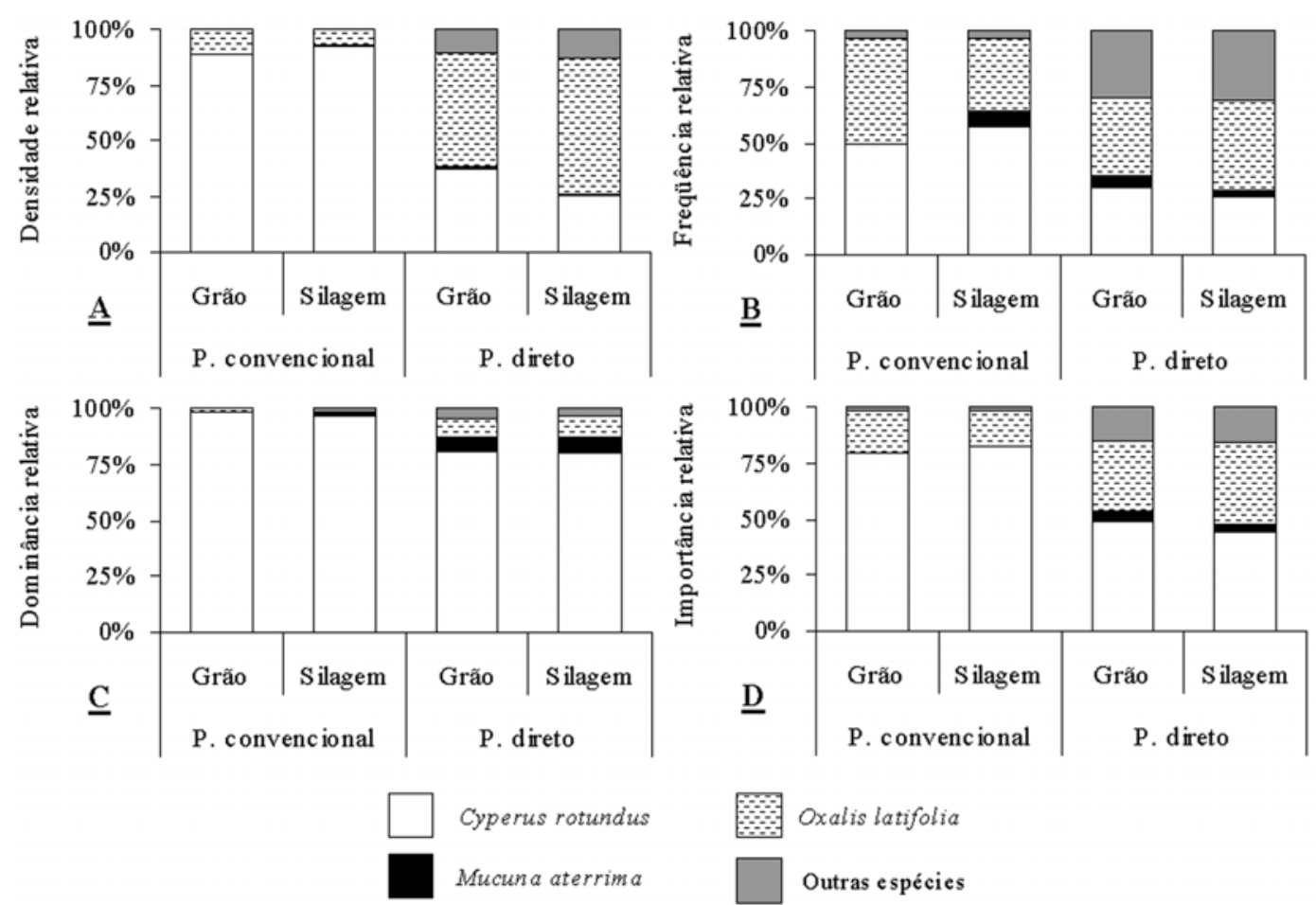

Oxalis latifolia

Outras espécies

Figura 6 - Efeitos dos sistemas de manejo do solo (plantios convencional e direto) e das finalidades de uso do milho (grão e silagem) no terceiro ano de condução sobre a densidade (A), freqüência (B), dominância (C) e importância relativa (D) das espécies daninhas na cultura do milho, avaliadas aos 20 DAE após a aplicação dos herbicidas atrazine e metolachlor em préemergência Viçosa-MG, 2001. (Outras espécies corresponde a Amaranthus deflexus, Bidens pilosa, Brachiaria plantaginea, Coronopus didymus, Digitaria horizontalis e Euphorbia heterophylla).

Ao observar a importância relativa das populações sob plantio direto nas avaliações que antecedem a aplicação dos herbicidas seletivos às culturas de milho (Figura 2D) e feijão (Figura 4D), verificou-se maior importância para dicotiledôneas em relação a Cyperus rotundus. Os maiores benefícios do plantio direto no controle de Cyperus rotundus foram proporcionados pela aplicação do glyphosate, que ocasionou morte das manifestações epígeas recém-emergidas e também de tubérculos, principalmente aqueles localizados próximo ao bulbo basal, e pela ausência do preparo mecânico devido à não-fragmentação de suas estruturas vegetativas no solo (Severich \& Franco, 2000).

No entanto, na cultura do milho os efeitos dos herbicidas seletivos aplicados influenciaram a dinâmica populacional das espécies nos diferentes agroecossistemas (Figuras 3D e 6D). Esses efeitos contribuíram para o aumento da densidade, dominância e importância relativa de Cyperus rotundus em todos os tratamentos, mesmo com baixa densidade de indivíduos sob plantio direto nas avaliações anteriores. Isso ocorreu porque a aplicação dos herbicidas na cultura do milho proporcionou controle eficiente de dicotiledôneas anuais, principalmente de Amaranthus deflexus, e insatisfatório para espécies de propagação vegetativa (ciperáceas e trevo), conforme observado, também, por Dobbels \& Kapusta (1993). A mistura de nicosulfuron e atrazine aplicados em pósemergência não proporcionou bom controle de Digitaria horizontalis (Figura 3D), confirmando resultados obtidos por Archângelo et al. (1995). No caso da cultura do feijão, não foi verificado controle eficiente para Coronopus didymus, com os herbicidas fluazifop-p-butil e fomesafen obtendo maior importância relativa aos $40 \mathrm{DAE}$ (Figura 5D).

Quanto a Mucuna aterrima, verificou-se sua presença em todos os tratamentos na cultura do milho, ocorrendo, todavia, com maior 
importância relativa no plantio direto (Figuras 3D e 6D). A maior importância relativa desta espécie se deve provavelmente à localização da maior parte das sementes próximas à superfície do solo no plantio direto, ao passo que no sistema de plantio convencional elas foram distribuídas ao acaso no perfil do solo trabalhado. Como conseqüência, a maior concentração de sementes nas camadas superiores pode produzir períodos de germinação sincronizados, com maior densidade de plântulas dentro de um curto período de tempo. Dessa forma, a depleção do banco de sementes de Mucuna aterrima em sistemas onde não ocorre o revolvimento do solo é maior, desde que não ocorra o reabastecimento desse banco.

\section{LITERATURA CITADA}

ARCHÂNGELO, E. R.; KARAM, D.; SILVA, J. B. Controle de plantas daninhas na cultura do milho com a mistura de atrazine + nicosulfuron. In: CONGRESSO BRASILEIRO DE CIÊNCIA DAS PLANTAS DANINHAS, 20., 1995, Florianópolis. Resumos... Florianópolis: Sociedade Brasileira da Ciência das Plantas Daninhas, 1995. p. 174.

BULHER, D. D. et al. Integrating mechanical weeding with reduced herbicide use in conservation tillage corn production systems. Agron. J., v. 87, p. 507-512, 1995.

BULHER, D. D.; MESTER, T. C.; KOLHER, K. A. The effect of maize residues and tillage on emergence of Setaria faberi, Abutilon theophrasti, Amaranthus retroflexus e Chenopodium album. Weed Res., v. 36, p. 153-165, 1996.

CRUTCHFIELD, D. A.; WICKS, G. A.; BURNISE, O. C. Effect of winter wheat (Triticum aestivum) straw mulch level on weed control. Weed Sci., v.34, p.110-114, 1986.

DOBBELS, A. F.; KAPUSTA, G. Post emergence weed control in corn (Zea mays) with nicosulfuron combinations. Weed Technol., v. 7, p. 844-850, 1993.

FERREIRA, F. A. et al. Manejo integrado de plantas daninhas em hortaliças. In: ZAMBOLIM, L. (Ed.). MANEJO INTEGRADO DE DOENÇAS, PRAGAS E PLANTAS DANINHAS, 2000, Viçosa. Palestras... Viçosa: 2000. p. $365-372$.

GHADIRI, H.; SHEA, P. J.; WICKS, G. A. Interception and retention of atrazine by wheat (Triticum aestivum) stubble. Weed Sci., v. 34, p. 502-506, 1984.
GODOY, G.; VEGA, J.; PITTY, A. El tipo de labranza afecta la flora y la distribución vertical del banco de semillas de malezas. Ceiba, v. 36, n. 2, p. 217-229, 1995.

GUERSA, C. M.; MARTÍNEZ-GUERSA, M. A. Ecological correlates of seed size and persistence in the soil under different tilling systems: Implications for weed management. Field Crops Res., v. 67, p. 141-148, 2000.

JOHNSON, M. D.; WYSE, D. L.; LUESCHEN, W. E. The influence of herbicide formulation on weed control in four tillage systems. Weed Sci., v. 37, p. 239-249, 1989.

KREBS, C. J. Ecology: the experimental analysis of distribution and abundance. New York: Harper \& Row Publisher, 1985. p. 513-572.

LINDQUIST, J. L.; MAXWELL, B. D. The horizontal dispersal pattern of weed seed surrogates by farms machinery. Proc. North Center Weed Sci. Soc., v. 46, p. 108-109, 1991.

MEIRONG, L. Leaf photosynthetic nitrogen-use efficiency of $\mathrm{C}_{3}$ and $\mathrm{C}_{4}$ Cyperus species. Photosynthetica, v. 29, n. 1, p. $117-130,1993$.

MILES, J. E.; NISHIMOTO, R. K.; KAWABATA, O. Diurnally alternating temperatures stimulates sprouting of purple nutsedge (Cyperus rotundus) tubers. Weed Sci., v. 44, p. 122-125, 1996.

MUluGUETA, D.; STOLTENBERG, D. E. Increase weed emergence and seed bank depletion by soil disturbance in no-tillage systems. Weed Sci., v. 45, p. 234-241, 1997.

ORYOKOT, J. O. E.; MURPHY, S. D.; SWANTON, C. J. Effect of tillage and corn on pigweed (Amaranthus spp.) seedling emergence and density. Weed Sci., v. 45, p. 120126, 1997.

PITELLI, R. A. Estudos fitossociológicos em comunidades infestantes de agroecossistemas. J. Conserb, v. 1, n. 2, p. 1-7, 2000a.

PITELLI, R. A. Estudo fitossociológico de uma comunidade infestante da cultura da cebola. J. Conserb, v. 1, n. 2, p. 1-6, 2000b.

SEVERICH, J. C.; FRANCO, P. No-till and glyphosate reduce the emergence and tuber bank of Cyperus rotundus. In: INTERNATIONAL WEED SCIENCE CONGRESS, 3., 2000, Foz do Iguaçu. Abstracts... Foz do Iguaçu: IWSS, 2000. p. 13.

ZELAYA, I. A.; OVEN, M. D. K.; PITTY, A. Effect of tillage and environment on weed population dynamics in the dry tropics. Ceiba, v. 38, n. 2, p. 123-135, 1997. 